\title{
Erratum to: A link mining algorithm for earnings forecast and trading
}

\author{
Germán Creamer · Sal Stolfo
}

Published online: 16 February 2010

(C) The Author(s) 2010

\section{Erratum to: Data Min Knowl Disc \\ DOI 10.1007/s10618-008-0124-z \\ (2009) 18:419-445}

The author regret for an error occurred in Fig. 1 of this article published in volume 18 , number 3, June 2009. In the denominator of equation $w_{i}^{t}$, the sign of $y_{i}$ should be positive instead of negative. The corrected figure is given below.

$$
\begin{aligned}
& F_{0}(x) \equiv 0 \\
& \text { for } t=1 \ldots T \\
& w_{i}^{t}=\frac{1}{1+e^{y_{i} F_{t-1}\left(x_{i}\right)}} \\
& \text { Get } h_{t} \text { from weak learner } \\
& \alpha_{t}=\frac{1}{2} \ln \left(\frac{\sum_{i: h_{t}\left(x_{i}\right)=1, y_{i}=1} w_{i}^{t}}{\sum_{i: h_{t}\left(x_{i}\right)=1, y_{i}=-1} w_{i}^{t}}\right) \\
& F_{t+1}=F_{t}+\alpha_{t} h_{t}
\end{aligned}
$$

Fig. 1 The Logitboost algorithm (Friedman et al. 2000). $y_{i}$ is the binary label to be predicted, $x_{i}$ corresponds to the features of an instance $i, w_{i}^{t}$ is the weight of instance $i$ at time $t, h_{t}$ and $F_{t}(x)$ are the prediction rule and the prediction score at time $t$, respectively

The online version of the original article can be found under doi:10.1007/s10618-008-0124-z.

G. Creamer $(\varangle) \cdot$ S. Stolfo

Department of Computer Science, Columbia University, 500 W 120 St, New York, NY 10027, USA

e-mail: ggc14@columbia.edu

S. Stolfo

e-mail: sal@cs.columbia.edu

G. Creamer

Centrum Catolica, Pontificia Universidad Católica del Peru, Lima, Peru

e-mail: gcreamer@pucp.edu.pe 